\title{
Investigation of Long Cellulose Fibre Reinforced and Injection Moulded Poly(lactic acid) Biocomposites
}

\author{
S. Hajba ${ }^{1}$, T. Tábi ${ }^{1,2}$ \\ ${ }^{1}$ Budapest University of Technology and Economics, Department of Polymer \\ Engineering \\ Muegyetem rkp. 3., 1111 Budapest, Hungary \\ e-mail: hajba@pt.bme.hu

\section{${ }^{2}$ MTA-BME Research Group for Composite Science and Technology Muegyetem rkp. 3., 1111 Budapest, Hungary} \\ Abstract: We investigated injection moulded composites of a polylactic acid \\ matrix reinforced with cellulose fibers. We produced long fiber \\ reinforced granules (preforms) with the use of two technologies: \\ extrusion coating and film stacking. We examined the effect of fiber \\ reinforcement and manufacturing technology on the properties of the \\ composites. $30 \mathrm{wt} \%$ fiber reinforcement caused an increase in both \\ strength and modulus compared to the reference PLA, and we also \\ managed to improve creep resistance.
}

Keywords: poly(lactic acid), biopolymer, biocomposite, cellulose fiber, injection moulding

\section{Introduction}

Nowadays even though crude oil prices are going down, the amount of bioplastics sold keep on growing and a great deal of effort is spent on their development, therefore more and more research projects focus on a biopolymer. According to estimates, petroleum reserves are enough for another 40 years or so but as crude oil is running out; its price is going to go up, making petroleum-based plastics more expensive, too. Although only 5-6\% of crude oil is used by the plastic industry each year, it is important to research for alternatives to replace petroleum-based polymers. Another serious problem is waste management, as conventional polymers take a very 
long time to decompose or do not decompose at all, and therefore present an enormous load on the environment. The use of biopolymers [1] (biodegradable polymers produced from renewable resources) can solve this problem; at the end of their lifetime, they can be decomposed into humus, water and carbon dioxide in the proper environment. However, some biopolymers have properties inferior to those of conventional polymers or are more expensive than petroleum-based polymers, which limits their widespread use. A prominent representative of biopolymers is polylactic acid (PLA), which is most similar to polyethylene terephthalate (PET) and polystyrene (PS) in terms of its structure and properties. Its high strength (50$60 \mathrm{MPa}$ ) and rigidity (3-4 GPa) make it stand out from other biopolymers but still, it is most extensively used in the packaging industry [2][3][4][5][6][7]. Creating composites is one way of making PLA suitable for engineering applications. If cellulose-based fibers are used as reinforcement [8][9][10][11][12][13], the composite will completely retain the biodegradability of PLA.

With the use of natural fibers, strength, modulus and impact strength can be improved, and the composite will also be biodegradable. Many papers have focused on PLA composites with various cellulose-based fibers as reinforcement, such as flax, hemp, cotton, jute, kenaf, and other natural and artificial cellulose fibers. A critical point of PLA composites reinforced with cellulose-based fibers is fibermatrix adhesion - its quality greatly affects the properties of the composite. It may happen that the strength of the composite is lower than that of the matrix even in the case of 47 vol\% reinforcement [14]. Researchers have used numerous surface treatment agents to improve adhesion between cellulose-based fibers and PLA [14][15][16][17][18][19][20]. Sawpan et al [15] investigated the effect of surface treatment on interfacial shear strength (IFSS) in the case of hemp and PLA. They subjected the fibers to alkali (PLA/ALK), silane (PLA/SIL), acetyl (PLA/ACY), maleic anhydride (PLA/MA), and combined alkali-silane (PLA/ALKSIL) surface treatment. They explained the difference between the different kinds of surface treatments with the $\mathrm{OH}$ side groups of the treated fiber, with which they can connect to the carbonyl and carboxyl groups of the PLA. Treatment with acetyl and maleic anhydride did not result in much improvement - researchers explained this with the fact that in the two surface treatments, the $\mathrm{OH}$ groups of the fiber are replaced by $\mathrm{CH} 3 \mathrm{CO}$ (acetate), and $\mathrm{COOH}$ (carboxyl) groups, as a result of which fewer $\mathrm{OH}$ groups can contribute to interfacial adhesion. Tokor et al [16] performed a similar IFSS test on bamboo fibers treated with an alkali and steaming, and Cho et al [17] as well, on jute and kenaf fibers treated with static and dynamic soaking. In both cases, the researchers showed that surface treatment improved adhesion, which was indicated by the increase in interfacial shear strength. Huda et al [14] investigated the effect of alkali and silane surface treatment on kenaf/PLA composites. As fiber content increased, flexural modulus increased as well, but strength decreased 
initially, which the researchers attributed to the inferior adhesion between the fibers and the PLA. The alkali/silane combined surface treatment resulted in a considerable increase of modulus from $27 \mathrm{vol} \%$, and all surface treatments led to better mechanical properties. However, even this increased strength is less than the strength of PLA, which can be attributed to the structural damage and strength decrease of the kenaf fibers as a result of surface treatment. Surface treatment on the other hand, considerably improved the notched Izod impact strength of the composites (alkali treatment improved it by 50\%), and the heat deflection temperature also increased from $65{ }^{\circ} \mathrm{C}$ to $174{ }^{\circ} \mathrm{C}$ ), which the researchers attributed to improved fiber-matrix adhesion. This, however, should be viewed critically because the PLA they used had a melting temperature range of $150-180^{\circ} \mathrm{C}$. Storage modulus increased more than $100 \%$ as a result of the combined surface treatment.

In the literature, the most commonly used method to produce biocomposites is film stacking [18][19][20][21][22]. Its advantage is that up to $70 \mathrm{wt} \%$ fiber content can be achieved, as opposed to the $30 \mathrm{wt} \%$ achievable by injection moulding, which allows considerable improvement in properties. Ochi's [19] $70 \mathrm{wt} \%$ kenafreinforced composites manufactured by film stacking had a tensile strength of $223 \mathrm{MPa}$ and a flexural strength of $254 \mathrm{MPa}$; modulus values were around $22 \mathrm{GPa}$. in spite of the considerable improvement, he also mentions imperfect adhesion.

Injection moulding can produce products of far more complicated geometry than film stacking but maximum fiber content and fiber length are lower as during extrusion and injection moulding, fibers are broken. Bledzki et al [23][24] compared injection moulded polypropylene and polylactic acid based biocomposites with $30 \mathrm{wt} \%$ fiber content. They found that the best composite was cellulose fiber reinforced PLA both in terms of strength and impact strength. The researchers attributed this to the far more uniform quality of regenerated cellulose than that of plant fibers, and also mentioned that fiber matrix adhesion is critical, and that too high processing temperatures can cause the cellulose fibers to degrade. The achievable maximum tensile strength and modulus are lower than in the case of filmstacked composites; tensile strength was $92 \mathrm{MPa}$ and modulus was 6.5 GPa. Many research projects [25][26][27][28] yielded similar results; lower fiber content than in the case of film stacking results in less improvement in strength and other properties.

Based on the literature, it can be concluded that in the case of these biocomposites, the most important task is to create proper adhesion. If adhesion is good, fiber reinforcement can considerable improve the strength, impact strength and heat deflection temperature of PLA. In some cases, however, the strength of the fiberreinforced composite did not even reach that of pure PLA. Many surface treatment agents have been tried but alkali and silane treatment proved the best. A great 
disadvantage of surface treatment agents is that they are poisonous and dangerous; therefore, their application is complicated and treatment takes a long time. In most cases, the composites were manufactured by film stacking, which greatly improved strength parameters due to high fiber content. Injection moulding was only used in a few cases, mostly due to the low achievable fiber content.

\section{Materials and methods}

Injection moulding grade PLA type 3052D from NatureWorks was used in our research with a D-Lactide content of around 4\%. 3052D PLA has a density of $1.24 \mathrm{~g} / \mathrm{cm} 3$, a $\mathrm{T}_{\mathrm{g}}$ range of $55-60{ }^{\circ} \mathrm{C}$, a melting temperature range of $145-160{ }^{\circ} \mathrm{C}$ and a melt flow index of $14 \mathrm{~g} / 10 \mathrm{~min}$ (at $210^{\circ} \mathrm{C}$, with a $2.16 \mathrm{~kg}$ load). PLA was dried for 6 hours at $80^{\circ} \mathrm{C}$ before biocomposite production. We used Viscord Bohemia Super 2 type regenerated cellulose fibers from Glanzstoff Bohemia. Its linear density is 2440 dtex, the number of fibers in a roving is 1320 .

The long fiber preforms necessary for the tests were prepared with two technologies (Fig. 1.). One was extrusion coating. We produced the long-fiber granules with a coating tool fitted to a Labtech LTE 26-44 twin-screw extruder, and fiber puller and pelletizer connected to it. We varied fiber content by modifying the rotational speed of the extruder, the fiber pulling speed, and the amount of fibers entered into the die. At an extruder screw rotational speed of $101 / \mathrm{min}$ and a pulling speed of $12 \mathrm{~m} / \mathrm{min}$, in the case of 2 cellulose rovings, fiber content was $15 \mathrm{wt} \%$, while in the case of 4 cellulose rovings, it was $30 \mathrm{wt} \%$. The other method of making long-fiber granules was film stacking, with which we produced thin sheets containing $30 \mathrm{wt} \%$ fibers. We then cut these sheets into $10 \mathrm{~mm}$ long pieces.

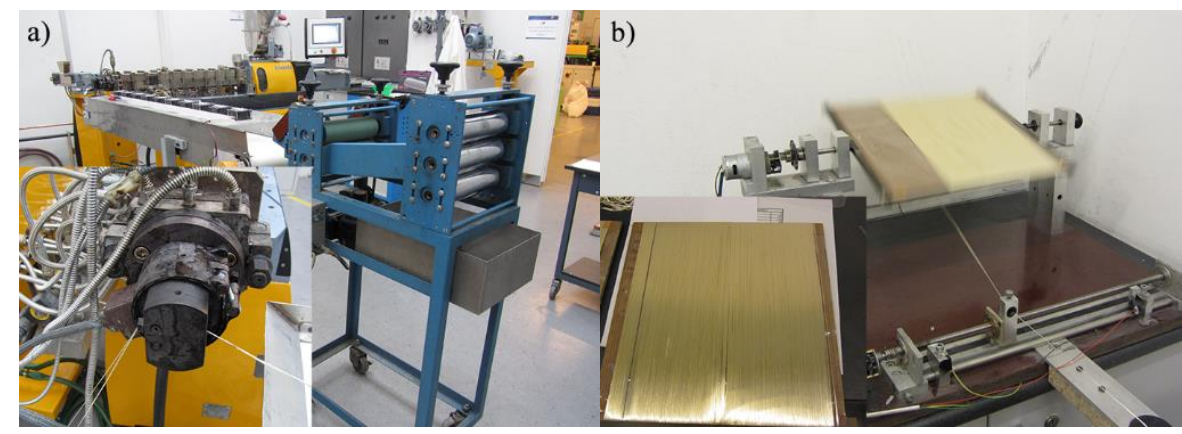

Figure 1. PLA/cellulose composite preform manufacturing: extrusion coating a) and winding plus film stacking $b$ )

$10 \mathrm{~mm}$ initial pellet length were used since it was possible to make this pellet size in both technologies. Additionally, higher than $10 \mathrm{~mm}$ and lower than $5 \mathrm{~mm}$ pellet 
lengths were also investigated in a tests not presented in this paper, since both pellet length ranges were rejected. The usage of higher pellet length was rejected due to very high fibre distribution inhomogeneity, while the usage of lower pellet length was also rejected since the fibres pull-out from the pellets during cutting. Accordingly, in our paper, based on these previous tests, the effect of initial pellet length of 5, 7, and $10 \mathrm{~mm}$ was investigated. The specimens were produced by injection moulding from types of both long-fiber granules. An Arburg Allrounder 370S 700-290 injection moulding machine was used for this. Melt temperature was $170-230{ }^{\circ} \mathrm{C}$, and mold temperature was $25^{\circ} \mathrm{C}$. Shot volume was $43 \mathrm{~cm}^{3}$, switchover volume was $12 \mathrm{~cm}^{3}$, screw rotational speed was $15 \mathrm{~m} / \mathrm{min}$, holding pressure and holding time were $600 \mathrm{bar}$ and $20 \mathrm{~s}$, and residual cooling time was $40 \mathrm{~s}$. The designation of samples produced by coating and injection moulding was C+IM, while the designation of samples made by film stacking and injection moulding was HP+IM.

Differential Scanning Calorimetry measurements were performed on a TA Instruments Q2000 type calorimeter (NewCastle, USA). 3-6 mg samples were taken from the middle of the cross-section of the injection moulded specimens. Firstly, we took the samples from unannealed injection moulded specimens and performed isothermal measurements to determine necessary annealing times. Secondly, after annealing the injection moulded specimens for various times or at various temperatures, we examined the samples in non-isothermal mode (heat/cool/heat) from 0 to $200{ }^{\circ} \mathrm{C}$ at a heating/cooling rate of $5{ }^{\circ} \mathrm{C} / \mathrm{min}$ to determine the glass transition temperature $\left(\mathrm{T}_{\mathrm{g}}\right)$, cold crystallization temperature $\left(\mathrm{T}_{\mathrm{cc}}\right)$, enthalpy of coldcrystallization $(\Delta \mathrm{Hcc})$, melting temperature $\left(\mathrm{T}_{\mathrm{m}}\right)$, and the enthalpy of fusion $(\Delta \mathrm{Hm})$. Crystallinity was calculated from the first heating scan of the injection moulded specimens with Eq. (1):

$$
X_{c}=\frac{\Delta H_{m}-\Delta H_{c c}}{\Delta H_{f} \cdot(1-a)} \cdot 100 \%,
$$

where $\mathrm{X}_{\mathrm{c}}(\%)$ is the calculated crystallinity, $\Delta \mathrm{H}_{\mathrm{m}}(\mathrm{J} / \mathrm{g})$ and $\Delta \mathrm{H}_{\mathrm{cc}}(\mathrm{J} / \mathrm{g})$ are the enthalpy of fusion and the enthalpy of cold crystallization, respectively, a [-] is fiber content, and $\Delta \mathrm{H}_{\mathrm{f}}(\mathrm{J} / \mathrm{g})$ is the enthalpy of fusion for $100 \%$ crystalline PLA $(93.1 \mathrm{~J} / \mathrm{g})$ [3].

Heat Deflection Temperature measurements were performed on a Ceast HV3 type HDT (Torino, Italy) measuring equipment, according to the ISO 75:2013 standard. HDT B type measurements were carried out in flatwise mode with a loading stress of $0.45 \mathrm{MPa}$, heating rate of $2{ }^{\circ} \mathrm{C} / \mathrm{min}\left(120^{\circ} \mathrm{C} /\right.$ hour $)$ and with a span length of $64 \mathrm{~mm}$.

The mechanical properties of the annealed and unannealed PLA specimens were analyzed with tensile, flexural and Charpy tests, based on MSZ EN ISO 527:2012, 
MSZ EN ISO 178:2011 and MSZ EN ISO 179:2010 respectively. The tensile and the flexural tests were performed on a Zwick Z020 universal testing machine (Ulm, Germany), equipped with a Zwick BZ 020/TN2S force measuring cell with a force limit of $20 \mathrm{kN}$, with a crosshead speed of $5 \mathrm{~mm} / \mathrm{min}$. The Charpy impact tests were performed on unnotched samples with a Ceast Resil Impactor (Torino, Italy) impact testing machine equipped with a $2 \mathrm{~J}$ impact energy hammer and a DAS8000 data collector unit. All of the tests were performed at room temperature and at a relative humidity of $50 \pm 10 \%$.

Scanning electron microscopy (SEM) was performed with a Jeol JSM 6380LA type electron microscope. The fracture surfaces of the tensile specimens were used for the observations. An $\mathrm{Au} / \mathrm{Pd}$ alloy was sputtered onto the surface prior to observation to avoid electrostatic charging.

\section{Results and discussion}

After coating it can be seen that fiber reinforcement is in the middle, and it is surrounded by the PLA matrix. The image of higher magnification clearly shows that there is little PLA between the introduced fiber bundles. The dispersion of fibers during injection moulding may be made more difficult by the fact that the fiber bundle remained as one whole after coating. (Fig. 2.).

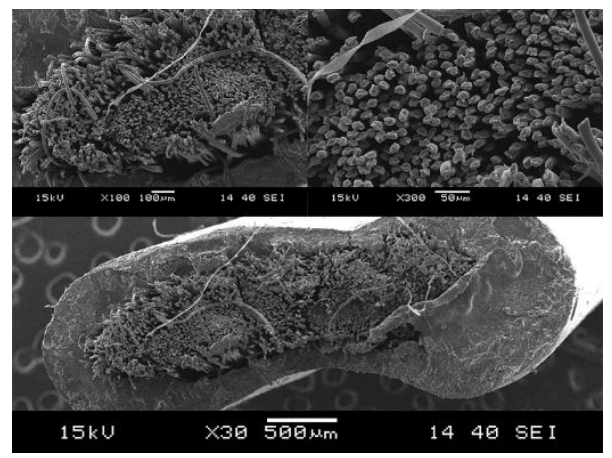

Figure 2. The structure of the composite preform made with extrusion coating

In the case of the preform produced by film stacking (Fig. 3.), the fiber bundles do not form a whole unit so much and there is matrix material between the fibers. This way during subsequent injection moulding, the fibers can be dispersed better, which can result in better properties of the composite. 


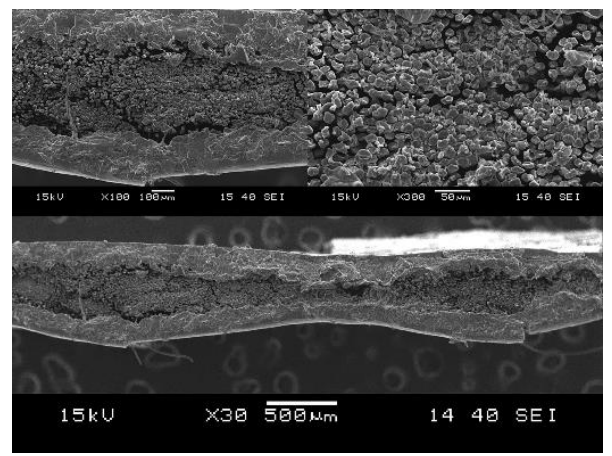

Figure 3. The structure of the composite preform made with film stacking

First, we performed tensile, flexural and Charpy impact tests on the long-fiber injection moulded PLA/cellulose composites. The average fiber content of the composites was 15 and $30 \mathrm{wt} \%$. We managed to achieve improvement in strength and impact strength with the use of cellulose fibers even at low fiber content ( 15 wt \%). Cellulose fibers did not improve tensile strength and modulus much, but they increased flexural strength from 97.8 $\mathrm{MPa}$ to $133.3 \mathrm{MPa}$, and modulus from $3.4 \mathrm{GPa}$ to $5.3 \mathrm{GPa}$ (Fig. 4.). At higher fiber content, tensile elasticity modulus decreased due to the inferior dispersion of fibers (Fig. 4).
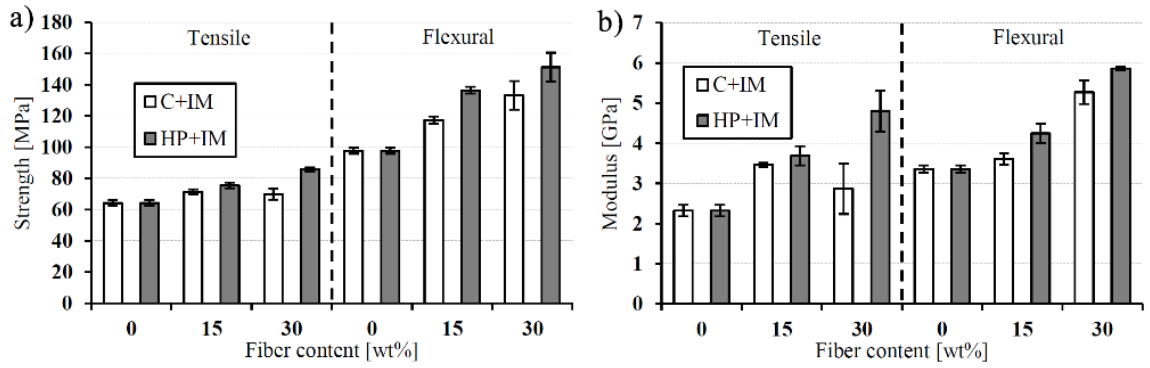

Figure 4. PLA/cellulose strength a) and modulus b)

Cellulose fibers improved both Charpy impact strength and thermal dimensional stability. In the case of both properties, PLA and the composite had the roughly same values up $15 \mathrm{wt} \%$ fiber content, while both the toughness and heat deflection temperature of the composite containing $30 \mathrm{wt} \%$ fibers increased. Charpy impact strength doubled and the heat deflection temperature increased by $25^{\circ} \mathrm{C}$ (Fig. 5.). 

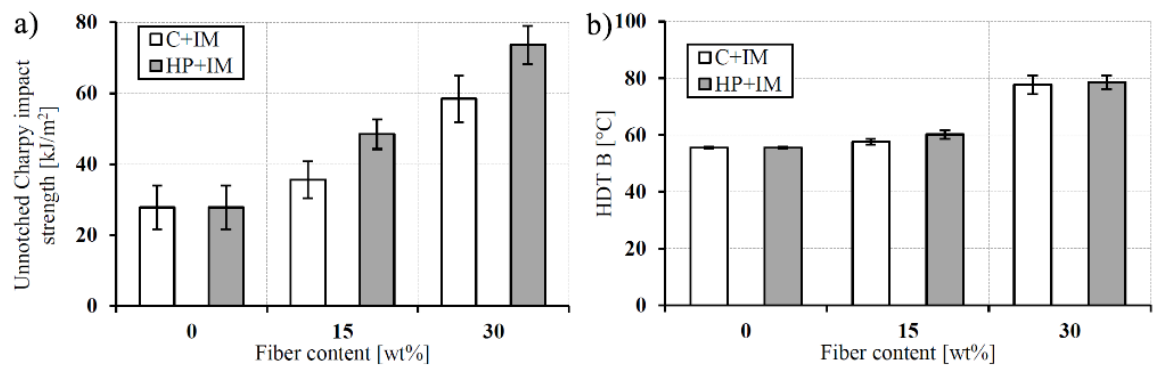

Figure 5. PLA/cellulose composites Charpy impact strength a) and heat deflection temperature $(H D T) b)$

Cellulose fibers can improve resistance to creep compared to pure PLA (Fig. 6.). At a load of $30 \mathrm{wt} \%$, the lifetime of composites injection moulded from film-stacked preforms is considerably longer, thanks to the better dispersed fibers in the composite. Obviously, the neglections applied by the approximation method, such as ambient temperature and its deviations, UV radiation and its effects, degradation and mechanical impacts have to be taken into account.

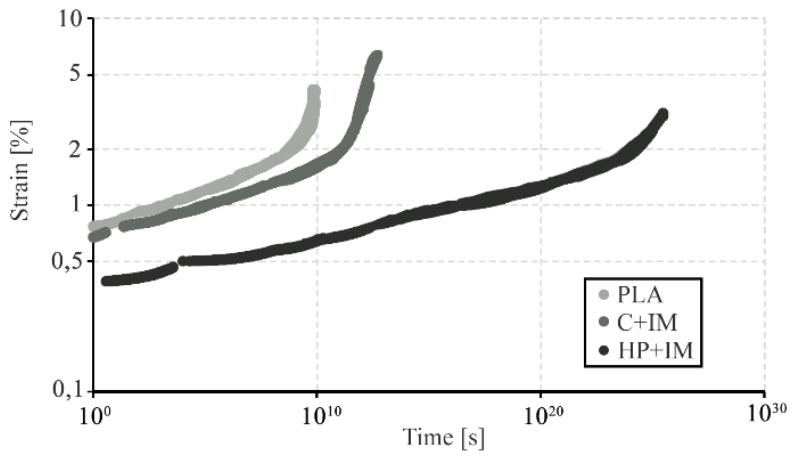

Figure 6. The master creep curves of PLA and long-fiber reinforce, injection moulded composite for a load level of $30 \%$

In the case of composites, we examined the effect of injection moulding parameters (melt temperature, injection speed, back pressure, screw rotational speed, initial granule length) on the properties of the composites. The results indicate that an increase in melt temperature (Fig. 7.), and injection speed (Fig. 8.), and a decrease in initial granule length (Fig. 9.) resulted in increased tensile strength and tensile elasticity modulus but did not affect Charpy impact strength. When melt temperature 
was increased from $170{ }^{\circ} \mathrm{C}$ to $230^{\circ} \mathrm{C}$, both tensile and flexural strength increased by nearly $30 \mathrm{MPa}$, but modulus did not change much.
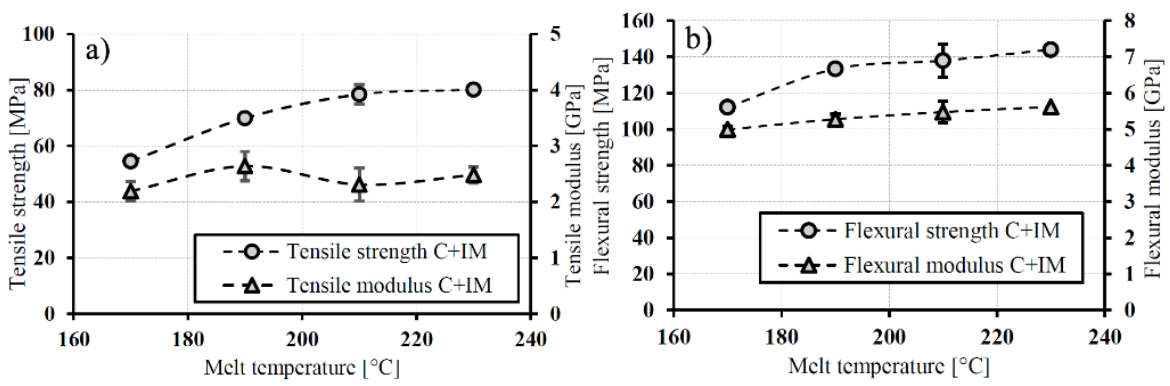

Figure 7. The effect of melt temperature on tensile a) and flexural b) strength and modulus

Reducing injection speed has a beneficial effect on the strength of the composite; probably because fiber breaking is reduced. Reducing injection speed to $10 \mathrm{~cm}^{3} / \mathrm{s}$ led to an increase in tensile strength by nearly $15 \mathrm{MPa}$.
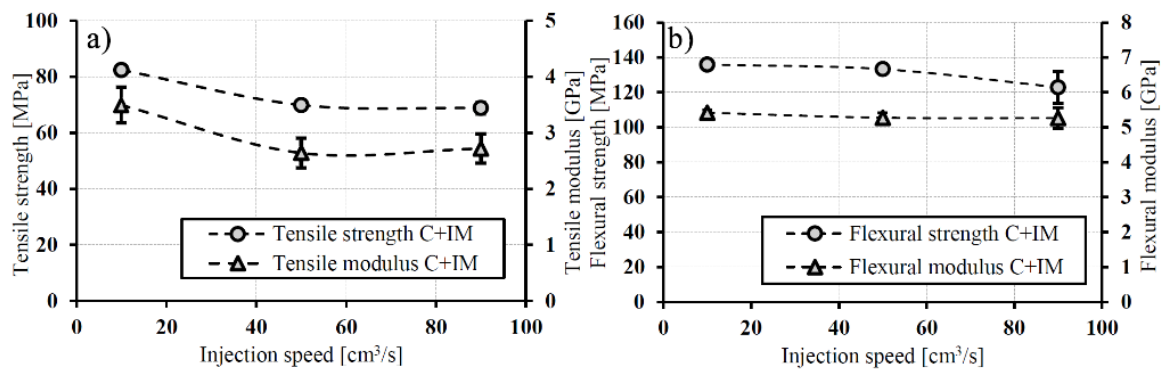

Figure 8. The effect of injection speed on tensile a) and flexural b) strength and modulus

The initial length of the long fiber granules affected the properties of the composite. Contrary to our expectations, the shorter pellet length was more effective in reinforcing capability due to the fact that shorter fibres could be more uniformly distributed in the specimens during injection moulding, while the long pellets caused inhomogeneity and increased stress concentration. The tensile and flexural strength of composites injection moulded from the shorter, $5 \mathrm{~mm}$ granules were slightly higher (by about $10 \mathrm{MPa}$ ) than in the case of the $10 \mathrm{~mm}$ granules. This is due to the fact that shorter fibers stick together less and are easier to disperse than longer fibers, which are more likely to form bundles, which also act as defect (Fig. 10.). A table has been constructed to present the results of Figure 7,8 and 9 numerically. 
S. Hajba and T. Tábi - Acta Technica Jaurinensis, Vol. 11, No. 3, pp. 150-164, 2018
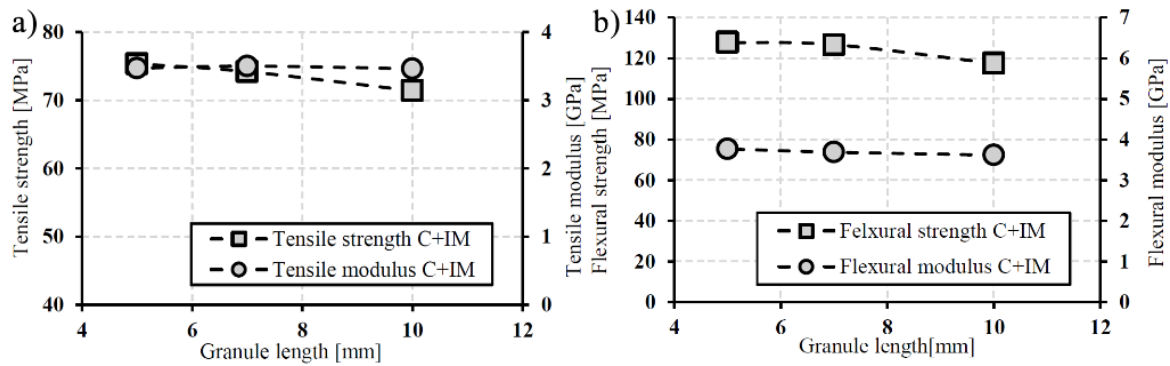

Figure 9. The effect of the initial length of the granules on tensile a) and flexural $b$ ) strength and modulus

Table 1. Mechanical properties of the injection molded composites

\begin{tabular}{|c|c|c|c|c|c|c|c|c|c|c|}
\hline \multirow{2}{*}{ Properties } & \multicolumn{4}{|c|}{ Melt temperature $\left[{ }^{\circ} \mathrm{C}\right]$} & \multicolumn{3}{c|}{ Injection speed } & \multicolumn{3}{c|}{ Granule length } \\
& $\mathbf{c}$ & $\left.\mathrm{cm}^{3} / \mathrm{s}\right]$ & \multicolumn{3}{c|}{$[\mathrm{mm}]$} \\
\hline & 170 & 190 & 210 & 230 & 10 & 50 & 90 & 5 & 7 & 10 \\
\hline $\begin{array}{c}\text { Tensile } \\
\text { strength } \\
{[\mathrm{MPa}]}\end{array}$ & $\begin{array}{c}54,5 \\
\pm 9,5\end{array}$ & $\begin{array}{c}69,9 \\
\pm 1,8\end{array}$ & $\begin{array}{c}78,4 \\
\pm 3,6\end{array}$ & $\begin{array}{c}80,1 \\
\pm 2,6\end{array}$ & $\begin{array}{c}82,4 \\
\pm 1,6\end{array}$ & $\begin{array}{c}69,9 \\
\pm 1,8\end{array}$ & $\begin{array}{c}68,8 \\
\pm 2,1\end{array}$ & $\begin{array}{c}75,4 \\
\pm 1,1\end{array}$ & $\begin{array}{c}74,2 \\
\pm 0,8\end{array}$ & $\begin{array}{c}71,4 \\
\pm 1,8\end{array}$ \\
\hline $\begin{array}{c}\text { Tensile } \\
\text { modulus } \\
{[\mathrm{GPa}]}\end{array}$ & $\begin{array}{c}2,2 \\
\pm 0,2\end{array}$ & $\begin{array}{c}2,6 \\
\pm 0,3\end{array}$ & $\begin{array}{c}2,3 \\
\pm 0,3\end{array}$ & $\begin{array}{c}2,5 \\
\pm 0,1\end{array}$ & $\begin{array}{c}3,5 \\
\pm 0,3\end{array}$ & $\begin{array}{c}2,6 \\
\pm 0,3\end{array}$ & $\begin{array}{c}2,7 \\
\pm 0,3\end{array}$ & $\begin{array}{c}3,5 \\
\pm 0,1\end{array}$ & $\begin{array}{c}3,5 \\
\pm 0,1\end{array}$ & $\begin{array}{c}3,5 \\
\pm 0,1\end{array}$ \\
\hline $\begin{array}{c}\text { Flexural } \\
\text { strength } \\
{[\mathrm{MPa}]}\end{array}$ & $\begin{array}{c}112,2 \\
\pm 7,2\end{array}$ & $\begin{array}{c}133,3 \\
\pm 4,6\end{array}$ & $\begin{array}{c}137,9 \\
\pm 4,5\end{array}$ & $\begin{array}{c}144,0 \\
\pm 5,2\end{array}$ & $\begin{array}{c}135,9 \\
\pm 2,2\end{array}$ & $\begin{array}{c}133,3 \\
\pm 4,6\end{array}$ & $\begin{array}{c}122,9 \\
\pm 2,7\end{array}$ & $\begin{array}{c}127,8 \\
\pm 1,5\end{array}$ & $\begin{array}{c}126,7 \\
\pm 2,0\end{array}$ & $\begin{array}{c}117,4 \\
\pm 2,3\end{array}$ \\
\hline $\begin{array}{c}\text { Flexural } \\
\text { modulus } \\
{[\mathrm{GPa}]}\end{array}$ & $\begin{array}{c}5,0 \\
\pm 0,2\end{array}$ & $\begin{array}{c}5,3 \\
\pm 0,2\end{array}$ & $\begin{array}{c}5,5 \\
\pm 0,2\end{array}$ & $\begin{array}{c}5,6 \\
\pm 0,2\end{array}$ & $\begin{array}{c}5,4 \\
\pm 0,2\end{array}$ & $\begin{array}{c}5,3 \\
\pm 0,2\end{array}$ & $\begin{array}{c}5,3 \\
\pm 0,1\end{array}$ & $\begin{array}{c}3,8 \\
\pm 0,2\end{array}$ & $\begin{array}{c}3,7 \\
\pm 0,2\end{array}$ & $\begin{array}{c}3,61 \\
\pm 0,1\end{array}$ \\
\hline
\end{tabular}



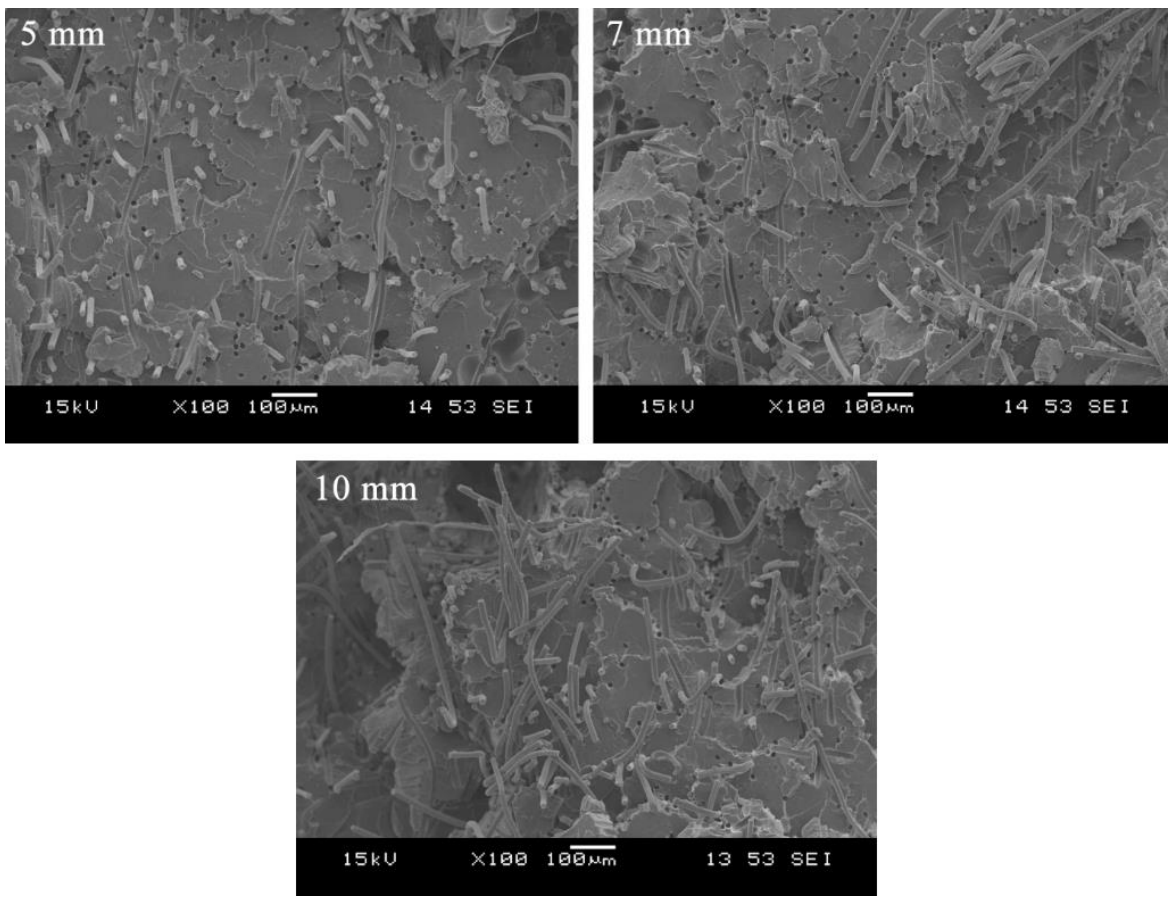

Figure 10. The fracture surfaces of injection moulded composites moulded from granules of different lengths $(57,10 \mathrm{~mm})$

\section{Summary}

In our work we produced long fiber reinforced granules with two different technologies for injection moulding. The maximum fibre content was $30 \mathrm{wt} \%$. Due to the long fibre reinforcement both the strength and the modulus were increased by $40 \%$ and 50\% respectively. Also the creep resistance was better of the composites compared to the neat PLA. Heat deflection temperature was also increased by $23{ }^{\circ} \mathrm{C}$ up to $78^{\circ} \mathrm{C}$.

\section{Acknowledgement}

The This research was supported by The National Research, Development and Innovation Office (NVKP_16-1-2016-0012). The authors thank Arburg Hungária Kft. for the Arburg Allrounder 370S 700-290 injection moulding machine, Lenzkes $\mathrm{GmbH}$ for the clamping tool system as well as Piovan Hungary Kft. and Tool-Temp Hungária Kft. for their support. 


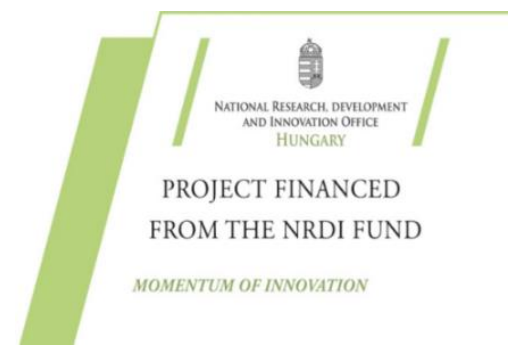

\section{References}

[1] G. Dogossy, T. Czigany, Thermoplastic starch composites reinforced by agricultural by-products: properties, biodegradability, and application, Journal of Reinforced Plastics and Composites 30 (21) (2011) pp. 1819-1825. DOI: $\underline{10.1177 / 0731684411429728}$

[2] D. Garlotta, A Literature review of poly(lactic acid), Journal of Polymers and the Environment, 9 (2) (2001) pp. 63-84.

DOI: $10.1023 / \mathrm{A}: 10202008$

[3] L-T. Lim, R. Auras, M. Rubino, Processing technologies for poly(lactic acid), Progress in Polymer Science 33 (8) (2008) pp. 820-852.

DOI: $10.1016 /$ j.progpolymsci.2008.05.004

[4] R. M. Rasal, A. V. Janorkar, D. E. Hirt, Poly(lactic acid) modifications, Progress in Polymer Science 35 (3) (2010) pp. 338-356.

DOI: $10.1016 /$ j.progpolymsci.2009.12.003

[5] F. Carrasco, P. Pages, J. Gámez-Pérez, O. O Santana, M. L. Maspoch, Processing of poly(lactic acid): Characterization of chemical structure, thermal stability and mechanical properties, Polymer Degradation and Stability 96 (2) (2010) pp. 116-125.

DOI: $10.1016 /$ j.polymdegradstab.2009.11.045

[6] G. Dogossy, Polymer foams, in: Zsoldos I (Ed.), Chapters on the latest automotive research areas of non-metallic materials, Széchenyi István University, Győr, 2015, pp. 212-245, in Hungarian.

[7] G. Dogossy, F. Ronkay, Foaming of recycled PET, in: Csibi-Venczel J (Ed.), OGÉT 2013: 21st International Conference on Mechanical Engineering, 
Erdélyi Magyar Műszaki Tudományos Társaság, Arad, pp. 97-100, 2013, in Hungarian.

[8] A. Bismarck, S. Mishra, T. Lampke, Plant Fibers as Reinforcement for green composites in: A. K. Mohanty, M. Misra, L. T. Drzal (eds): Natural fibers, biopolymers, and biocomposites, 1st edition, Taylor and Francis Group, Boca Raton, 2005, pp. 39-97.

[9] M. Ho, H. Wang, J. H. Lee, C. Ho, K. Lau, J. Leng, D. Hui, Critical factors on manufacturing process of natural fiber composites, Composites: Part B, 43 (8) (2012) pp. 3549-3562.

DOI: $10.1016 /$ j.compositesb.2011.10.001

[10] S. Hajba,T. Czigany, T. Tábi, Development of cellulose-reinforced Poly(Lactic Acid) (PLA) for engineering applications, Materials Science Forum 812 (1) (2015) pp. 59-64.

DOI: $10.4028 /$ www.scientific.net/MSF.812.59

[11] T. Mukherjee, N. Kao, PLA based biopolymer reinforced with natural fibre: A review, Journal of Polymer and Environment 19 (3) (2011) pp. 714-725. DOI: $10.1007 / \mathrm{s} 10924-011-0320-6$

[12] L. Shen, E. Worrell, M. K. Patel, Environmental impact assessment of manmade cellulose fibres, Resources, Conservation and Recycling, 55 (2) (2010) pp 260-274.

DOI: $\underline{10.1016 / j . r e s c o n r e c .2010 .10 .001}$

[13] P. White, M. Hayhurst, J. Taylor, A. Slater, Lyocell fibres, in: R. S. Blackburn (ed.): Biodegradable and sustainable fibres, 1st edition, Woodhead Publishing Limited, Cambridge, 2005, pp. 157-188.

[14] M. S. Huda, L. T. Drazal, A. K. Mohanty, M. Misra, Effect of fiber surfacetreatments on the properties of laminated biocomposites from poly(lactic acid) (PLA) and kenaf fibers, Composites Science and Technology 68 (2) (2008) pp. 424-432.

DOI: $10.1016 / \mathrm{j} . c o m p s c i t e c h .2007 .06 .022$

[15] M. A. Sawpan, K. L. Pickering, A. Fernyhough, Effect of fibre treatments on interfacial shear strength of hemp fibre reinforced polylactide and unsaturated polyester composites, Composites: Part A 42 () (2011) pp. 1189-1196.

DOI: 10.1016/j.compositesa.2011.05.003 
[16] R. Tokoro, D. M. Vu, K Okubo, T. Tanaka, T. Fujii, T. Fujiura, How to improve mechanical properties of polylactic acid with bamboo fibres, Journal of Materials Science 43 (2) (2008) pp. 775-787.

DOI: $10.1007 / \mathrm{s} 10853-007-1994-\mathrm{y}$

[17] D. Cho, J. M. Seo, H. S. Lee, C. W. Cho, S. O. Han, W. H. Park, Property improvement of natural fibre reinforced green composites by water treatment, Advanced Composite Materials 16 (4) (2007) pp. 299-314.

DOI: $\underline{10.1163 / 156855107782325249}$

[18] T. Nishino, K. Hirao, M. Kotera, K. Nakamae, H. Inagaki, Kenaf reinforced biodegradable composite, Composites Science and Technology 63 (9) (2003) pp. 1281-1286.

DOI: $10.1016 / \mathrm{S} 0266-3538(03) 00099-\mathrm{X}$

[19] S. Ochi, Mechanical properties of kenaf fibres and kenaf/PLA composites, Mechanics of Materials 40 (4-5) (2008) pp. 446-452.

DOI: $\underline{10.1016 / j . m e c h m a t .2007 .10 .006}$

[20] X. Li, G. L. Tabil, S. Panigrahi, Chemical treatments of natural fiber for use in natural fiber reinforced composites: A review, Journal of Polymer and Environment 15 (1) (2007) pp. 25-33.

DOI: $10.1007 / \mathrm{s} 10924-006-0042-3$

[21] N. Graupner, A. S. Hermann, J. Müssig, Natural and man-made cellulose fibre-reinforced poly(lactic acid) (PLA) composites: An overview about mechanical characteristics and application areas, Composites: Part A 40 (6-7) (2009) pp. 810-820.

DOI: $10.1016 /$ j.compositesa.2009.04.003

[22] K. Oksman, M. Skrifvars, J.-F Selin, Natural fibres as reinforcement in polylactic acid (PLA) composites, Composites Science and Technology 63 (9) (2003) pp. 1317-1324.

DOI: $10.1016 / \mathrm{S} 0266-3538(03) 00103-9$

[23] A. K. Bledzki, A. Jaszkiewicz, Mechanical performance of biocomposites based on PLA and PHBV reinforced with natural fibres - A comparative study to PP, Composites Science and Technology 70 (12) (2010) pp. 16871696.

DOI: $\underline{10.1016 / j . c o m p s c i t e c h .2010 .06 .005}$ 
[24] A. K. Bledzki, A. Jaszkiewicz, D. Scherzer, Mechanical properties of PLA composites with man-made cellulose and abaca fibres, Composites: Part A 40 (4) (2009) pp. 404-412.

DOI: $\underline{10.1016 / \mathrm{j} . c o m p o s i t e s a .2009 .01 .002}$

[25] B. Asaithambi, G. Ganesan, S. Ananda Kumar, Bio-composites:

Development and Mechanical Characterization of Banana/Sisal Fibre Reinforced Poly Lactic Acid (PLA) Hybrid Composites, Fibers and Polymers 15 (4) (2014) pp. 847-854.

DOI: $\underline{10.1007 / \mathrm{s} 12221-014-0847-\mathrm{y}}$

[26] A. A. Yussuf, I. Massoumi, A. Hassan, Comparison of polylactic acid/kenaf and polylactic acid/rise husk composites: The influence of the natural fibers on the mechanical, thermal and biodegradability properties, Journal of Polymers and Environment 18 (3) (2010) pp. 422-429.

DOI: $10.1007 / \mathrm{s} 10924-010-0185-0$

[27] N. C. Loureiro, J. L. Esteves, J. C. Viana, S. Ghosh, Development of polyhydroxyalkanoates/poly(lactic acid) composites reinforced with cellulosic fibers, Composites: Part B 60 (1) (2014) pp. 603-611.

DOI: $\underline{10.1016 / \mathrm{j} . \text { compositesb.2014.01.001 }}$

[28] B. Bax, J. Müssig, Impact and tensile properties of PLA/Cordenka and PLA/Flax composites, Composites Science and Technology 68 (7-8) (2008) pp. 1601-1607.

DOI: $10.1016 /$ j.compscitech.2008.01.004 